\title{
Human perception of vibrations according different assessment methods
}

\author{
Alicja Kowalska Koczwara ${ }^{1}$, Krzysztof Stypuła ${ }^{2}$ \\ Cracow University of Technology, Warszawska 24 St., 31-155 Krakow, Poland \\ ${ }^{1}$ Corresponding author \\ E-mail: ${ }^{1}$ akowalska@pk.edu.pl, ${ }^{2} k s t y p u l a @ p k . e d u . p l$ \\ Received 5 September 2017; accepted 6 September 2017 \\ DOI https://doi.org/10.21595/vp.2017.19059
}

Check for updates

\begin{abstract}
Human perception of vibration could be the basic parameter in designing new buildings subjected to different type of transport vibrations. Humans are more sensitive for vibrations then building structure. In an increasingly urbanized city centres people are exposed to vibrations from different transport sources such as: tramways, railways, heavy truck traffic or subway especially when considered shallow underground. The aim of this paper is to investigate the use of two different evaluation methods of human perception of vibrations. Methods chosen for evaluation are: the basic root mean squared (RMS) method and the additional method of evaluation vibration dose value (VDV). The building chosen for analysis is subjected to three different vibration sources: tram, heavy truck and subway passages. It is located in Warsaw where is a shallow underground which could have significant influence on human response to vibrations because vibrations from this kind of source is more perceptible on lower floors. That is why measurement points were located in the middle of the floor on the ground floor and on the top floor. The registered signal from the three different sources of vibration was analysed according to RMS and VDV procedure included in ISO standard. RMS and VDV methods were compared with each other.
\end{abstract}

Keywords: vibrations, human perception, RMS method, VDV, transport vibration.

\section{Introduction}

In the last 25 years there has been rapid development of cities in Poland, at the same time there was an increase of residents' awareness about the environmental influences. People not only want to be an owner of an apartment or a house, but want to have assured the comfort in their resting places whether in the workplace. One of the aspect of indoor comfort is to ensure vibrational comfort in places occupied by people. Human perception of vibration is the main designing parameter for building subjected to dynamic influences because people are more sensitive than the structure of the building. Simultaneously human perception of vibration is a very subjective parameter which is better to investigate during in-situ measurements.

History of measurements of human perception of vibrations starts in early thirties of last century when Reiher and Meister's human response criteria appeared [1]. Then were some breaking points in developing of human perception during twentieth century like Wiss and Parmelee empirical formula [2] which was the basis of procedure included in ISO standard from 1974 [3]. Procedure in this first edition of ISO standard was not really precise. There were some levels of human vibration perception from imperceptible to comfortless (from level 1 to 5). This standard was not very useful. That is why in middle eighties second edition of ISO standard appeared [4]. The evaluation method included in that edition of the ISO standard is used by many researches till nowadays and it is the basis of many national standards of human perception of vibrations. This method called Root Mean Squared method (RMS) is the result of research conducted by Irwin [5]. This is the main procedure for human perception of vibration.

After that many researchers analyzed human response to vibration by different loading and application. There were analyzed different kind of excitation: impulse [6], walking [7], transport vibration [8], wind [9] and different types of application like: residential [10], commercial [11] or office buildings [12]. Researches like Griffin, Howarth, Mansfield during they long experience in 
analyzing of different physical quantities (acceleration and velocity), different assessment methods (running RMS method, RMS method and fourth power vibration dose method) and different frequency weighting curves, researched evaluation of human body comfort proposed evaluation method of vibration dose value (VDV) which is more sensitive for peaks in recorded signal then RMS method. It is worth noting that VDV method fully takes into account the time of exposure to vibrations. This method is the only method included in British standard of human exposure to vibrations [13].

In latest version of ISO standard [14] there is one more methods of assessment: the running RMS method and the associated maximum transient vibration value (MTVV) but it is not as popular as RMS or VDV method. That is why in this paper only RMS and VDV methods were considered

\section{Evaluation procedures}

\subsection{RMS method}

RMS method according to latest update of ISO standard [14] is called "basic evaluation method" and it is defined using weighted RMS acceleration which should be calculated according to following formula:

$a_{w}=\left[\frac{1}{T} \int_{0}^{T} a_{w}^{2}(t) d t\right]^{1 / 2}$.

In the same standard, there are guidelines for frequency weighted functions $w_{k}$ (weighted function in $z$ direction) and $w_{d}$ (weighted function in $x$ and $y$ direction) which are given in proper tables and illustrated in Fig. 1.

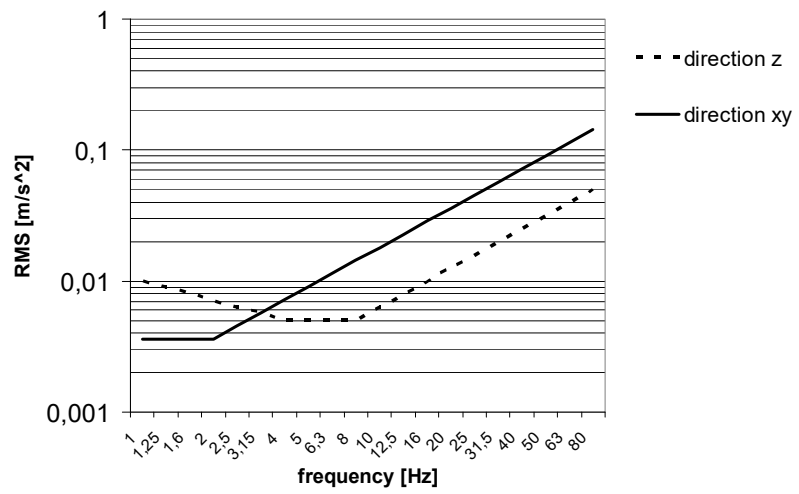

Fig. 1. Basic lines corresponding to vibration perception threshold

Weighted functions $w_{k}$ and $w_{d}$ are known as principal frequency weightings and their values in one-third octave band are also given in ISO standard. That is why the procedure to evaluate human perception of vibrations in buildings is simple.

Values of frequency weightings in one third octave band determine lines characterizing the so-called vibration perception threshold. Fig. 1 summarizes the sensitivity threshold lines received in the $z$ direction (feet to head) and in the $x y$ directions (back to chest, side by side). To create comfort lines form basic lines values defining these lines should be multiplied by the so-called correction factor " $n$ ". Values of factor " $n$ " are given in ISO standard [14] and they depend on destination of the room, time of occurrence of vibration, nature of vibrations and their repeatability. 


\subsection{VDV method}

VDV method in ISO standard [14] is an additional method which could be useful in situations when crest factor of the recorded signal is higher than 9. Crest factor is the modulus of the ratio of the maximum peak value of the signal to its RMS value. In practice, it means the signal with occasional shocks and transient vibrations. But it should be noticed that in British standard [13] VDV method is the only one method of assessment and in Australian standard [15] VDV method should be considered when the crest factor is equal 6 and higher.

The value of this parameter is determined by the formula:

$V D V=\left[\int_{0}^{T} a_{w}^{4}(t) d t\right]^{0.25}$.

The determined value of the vibration dose (VDV) is compared with the values given in standards $[13,15]$. In the appropriate table the three levels of sensitivity to vibration are described. Level one (low probability of complaints) is comparable with vibration perception threshold (Fig. 1). Highest level (adverse comments probable) could be compared with comfort limit. All three levels of vibration perception in residential rooms are listed in Table 1 [13].

Table 1. Levels of vibration perception in residential rooms for VDV procedure

\begin{tabular}{|c|c|c|c|}
\hline Room destination & $\begin{array}{c}\text { Low probability } \\
\text { of adverse comments }\end{array}$ & $\begin{array}{c}\text { Adverse comments } \\
\text { possible }\end{array}$ & $\begin{array}{c}\text { Adverse comments } \\
\text { probable }\end{array}$ \\
\hline Residential $16 \mathrm{~h}$ (day) & $0.2-0.4$ & $0.4-0.8$ & $0.8-1.6$ \\
\hline Residential $8 \mathrm{~h}$ (night) & $0.1-0.2$ & $0.2-0.4$ & $0.4-0.8$ \\
\hline
\end{tabular}

Assessment of human perception of vibrations caused by tram, heavy truck and subway.

The building chosen for analysis is the four-storey building with basement located in Warsaw caused by dynamic excitation from tram, subway and heavy truck passages. Measurement points were located at the first, second and fourth storey in the middle of residential room which is located close to excitation sources. Measurement lasted from 16.15 to 17.59. During that time, there were 26 passages registered: 11 trams, 10 subway, 1 heavy truck and 4 passages during which two different sources of vibration occurred. For all registered episodes RMS and VDV analysis were made.

\subsection{RMS analysis}

In 9 from registered 26 episodes vibration perception threshold was exceeded, in 5 of them also the comfort line during night was exceeded (" $n$ " factor equal 1.4) and in one episode both comfort lines during night and day (" $n$ " factor equal 4) were exceeded. The registered signal and RMS analysis for this extreme episode is shown on Fig. 2.

All exceedances occurred in $z$ direction. Most of them are from tram passages, only one is from simultaneously passing tram and subway.

\subsection{VDV analysis}

In VDV analysis the most important is proper calculation of overall day (16 h) or night ( $8 \mathrm{~h})$ exposure to vibration. That is why in [13] formula for so-called total value of VDV is given:

$V D V_{\text {total }}=\left[\sum_{i}^{N} V D V_{i}^{4}\right]^{1 / 4}$.

For every 26 vibration episodes VDV values were calculated and they are listed in Table 2. 


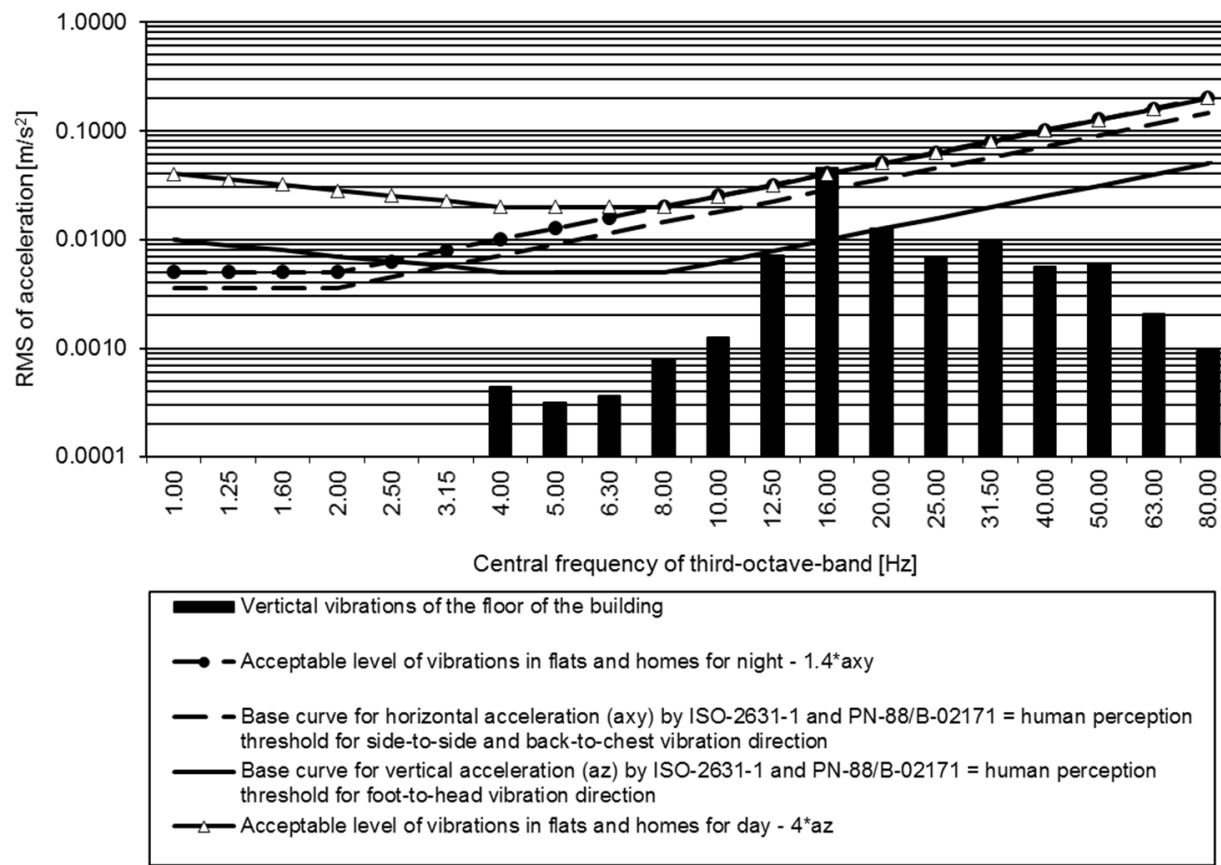

Fig. 2. RMS analysis for extreme episode of tram passages

Table 2. Values of VDV in three directions for all dynamic episodes

\begin{tabular}{|l|c|c|c|}
\hline \multicolumn{1}{|c|}{ Vibration source } & $V D V_{x}\left(\mathrm{~m} / \mathrm{s}^{1.75}\right)$ & $V D V_{y}\left(\mathrm{~m} / \mathrm{s}^{1.75}\right)$ & $V D V_{z}\left(\mathrm{~m} / \mathrm{s}^{1.75}\right)$ \\
\hline Tram (further truck) & 0.0051 & 0.0108 & 0.0502 \\
\hline Tram (closer truck) + Tram (further truck) & 0.0232 & 0.0138 & 0.2183 \\
\hline Tram (closer truck) & 0.0192 & 0.0099 & 0.0424 \\
\hline Tram (closer truck) & 0.0121 & 0.0210 & 0.2213 \\
\hline Tram (further truck) + Subway & 0.0009 & 0.0081 & 0.0381 \\
\hline Tram (closer truck) & 0,0082 & 0.0091 & 0.1511 \\
\hline Subway & 0.0016 & 0.0011 & 0.0102 \\
\hline Heavy truck & 0.0071 & 0.0022 & 0.1612 \\
\hline Subway & 0.0015 & 0.0014 & 0.0142 \\
\hline Tram (closer truck) & 0.0023 & 0.0027 & 0.0289 \\
\hline Subway & 0.0021 & 0.0020 & 0.0101 \\
\hline Subway & 0.0018 & 0.0015 & 0.0151 \\
\hline Tram (closer truck) & 0.0017 & 0.0019 & 0.0802 \\
\hline Tram (closer truck) & 0.0011 & 0.0012 & 0.0517 \\
\hline Subway & 0.0010 & 0.0012 & 0.0178 \\
\hline Tram (closer truck) & 0.0018 & 0.0019 & 0.1586 \\
\hline Subway & 0.0005 & 0.0003 & 0.0017 \\
\hline Tram (closer truck) & 0.0071 & 0.0063 & 0.2368 \\
\hline Subway & 0.0014 & 0.0015 & 0.0208 \\
\hline Subway & 0.0013 & 0.0012 & 0.0201 \\
\hline Tram (closer truck) & 0.0102 & 0.0104 & 0.1812 \\
\hline Tram (further truck) & 0.0139 & 0.0136 & 0.2008 \\
\hline Subway & 0.0049 & 0.0075 & 0.0403 \\
\hline Subway & 0.0042 & 0.0046 & 0.0129 \\
\hline Tram (closer truck) + Heavy truck & 0.0116 & 0.0137 & 0.0681 \\
\hline Tram (further truck) + Subway & 0.0031 & 0.0055 & 0.0151 \\
\hline
\end{tabular}

As can be seen from above Table values of VDV in $z$ direction are much higher than in both 
horizontal directions. Grey marked episode is the same for which RMS analysis is shown on Fig. 2. As also could be seen from Table 2 the highest $V D V$ values are vibrations caused by tram passages and these episodes influence on total value of $V D V$. Subway passages give the smallest excitations which means that, despite of the fact that Warsaw Metro is shallow subway, vibroinsulation was made properly.

Because $V D V$ values in $z$ direction are dominant and significant, $V D V_{\text {total }}$ for day and night were calculated for that direction only. Some assumptions were made: during the day, the same intensity of transport passages was assumed as for representative measurement, for the night according to the subway and tram timetables intensity of passages was assumed to be $25 \%$ of the representative. Appropriate values for day and night are as follows:

$V D V_{\text {day }}=0.5807-$ adverse comments possible;

$V D V_{\text {night }}=0.3453-$ adverse comments possible.

According VDV analysis comfort is not exceeded but residents may complain about vibrations.

\section{Conclusion}

Building taken to analysis is caused by three different vibration sources: tram, heavy truck and subway passages. Vibrations from subway may have crest factor higher than 9 [16]. In that kind of situation, the basic RMS method may underestimate the effects of vibration and according to ISO standard [14] one of additional method of evaluation should also be used. As additional method VDV value was chosen because of its application to signals with peaks and correlation with human sensation of vibration although it does not have physical meaning [17].

Analysis for all 26 recorded vibration episodes were made. RMS and VDV analysis are convergent. Results of RMS analysis shown exceedance of perception threshold for 9 episodes and for 5 of them also comfort limit during night is exceeded, in 1 case also comfort limit was exceeded during daytime. According VDV method also 9 vibration episodes are higher than 0.1 which could be interpreted as exceedance of perception threshold during night, 5 of them have VDV values higher than 0.2 which in turn could be interpreted as daytime exceedance of perception threshold. VDV values of every of these episodes is lower than 0.4 , so the comfort limit even for nighttime was not exceeded. But taking into account VDV values the whole time of vibration exposure should be considered. That is why total value of VDV during the night and day was calculated. Still comfort limit was not exceeded but both night and day VDV values indicate that adverse comments are possible because these values are in the intermittent range of VDV evaluation. Analyzing individual vibration episodes, it could be seen that tram passages will play the major role in these residents' complaints.

\section{References}

[1] Reiher H., Meister F. J. The Effect of Vibration on People. Forsch Gebeite Ingenieurwes, 1931, Vol. 2, p. 381-386 (in German). English Translation: Report No. F-TS-616-RE, Headquarters Air Material Command, Wright Field, Ohio, 1946.

[2] Wiss J. F., Parmelee R. A. Human perception of transient vibrations. Journal of the Structural Division, Vol. 4, 1974, p. 773-787.

[3] ISO 2631-1974(E), Guide for the Evaluation of Human Exposure to Whole Body Vibration.

[4] ISO 2631-2, Evaluation of human exposure to whole-body vibration - Part 2: Continuous and shockinduced vibration in buildings (1 to $80 \mathrm{~Hz}$ ), 1989.

[5] Irwin A. W. Human response to dynamic motion of structures. The Structural Engineer. Vol. 56A, Issue 9, 1978, p. 237-244.

[6] Griffin M. J., Whitham E. M. Discomfort produced by impulsive whole body vibration. Journal of the Acoustical Society of America, Vol. 68, 1980, p. 1277-1284.

[7] Ellingwood B., Tallin A. Structural serviceability: floor vibrations. Journal of Structural Engineering, Vol. 110, Issue 2, 1984, p. 410-9. 
[8] Howarth H. V. C., Whitham E. M. Human response to simulated intermittent railway induced building vibration. Journal of Sound and Vibration, Vol. 120, Issue 2, 1988, p. 413-420.

[9] Tamura Y., Kawana S., Nakamura O., Kanda J., Nakatà S. Evaluation perception of wind-induced vibration in buildings. Structures and Buildings, Vol. 159, 2006, p. 1-11.

[10] OhIsson S. V. A design approach for foot-induced floor vibration. Proceedings of the International Conference on Timber Engineering, Seattle, Washington, USA, 1988, p. 722-729.

[11] Murray T. M., Allen D. E., Ungar E. E. Floor Vibrations Due to Human Activity. Steel Design Guide 11. American Institute of Steel Construction, 1997.

[12] Allen D. E., Rainer J. H. Vibration criteria for long-span floors. Canadian Journal of Civil Engineering, Vol. 3, 1976, p. 165-173.

[13] BS 6472-1, Guide to Evaluation of Human Exposure to Vibration in Buildings, Part 1: Vibration Sources Other Than Blasting, 2008.

[14] ISO 2631-1, Mechanical Vibration and Shock - Evaluation of Human Exposure to Whole-Body Vibration - Part 1: General Requirements, 1997.

[15] AS 2670.2, Evaluation of Human Exposure to Whole-Body Vibration - Continuous and ShockInduced Vibration in Buildings (1 Hz to $80 \mathrm{~Hz}$ ). Council of Standards Australia, 1990.

[16] Yang Y., Liu P., Yin J. Research on assessment of fourth power vibration dose value in environmental vibration caused by metro. The 21st International Congress on Sound and Vibration, Beijing, China, 2014.

[17] Pavic A., Reynolds P., Waldron P., Bennett K. J. Critical review of guidelines for checking vibration serviceability of post-tensioned concrete floors. Cement and Concrete Composites, Vol. 23, Issue 1, 2001, p. 21-31. 